\title{
Association between self-reported sleep duration and dietary quality in European adolescents
}

Sarah Bel ${ }^{1}$, Nathalie Michels ${ }^{1}$, Tineke De Vriendt ${ }^{1,2}$, Emma Patterson ${ }^{3}$, Magdalena Cuenca-García ${ }^{4}$, Katharina Diethelm ${ }^{5}$, Bernard Gutin ${ }^{6}$, Evangelia Grammatikaki ${ }^{1,7}$, Yannis Manios ${ }^{7}$, Catherine Leclercq ${ }^{8}$, Francisco B. Ortega ${ }^{3,9}$, Luis A. Moreno ${ }^{10}$, Frederic Gottrand ${ }^{11}$, Marcela Gonzalez-Gross ${ }^{12,13}$, Kurt Widhalm $^{14}$, Anthony Kafatos ${ }^{15}$, Marta Garaulet ${ }^{16}$, Denes Molnar ${ }^{17}$, Jean-Marc Kaufman ${ }^{18}$, Chantal C. Gilbert ${ }^{19}$, Lena Hallström ${ }^{3,20}$, Michael Sjöström ${ }^{3}$, Ascensión Marcos ${ }^{21}$, Stefaan De Henauw ${ }^{1}$ and Inge Huybrechts ${ }^{1,22 *}$ on behalf of the HELENA Study Group $\dagger$

${ }^{1}$ Department of Public Health, Faculty of Medicine and Health Sciences, Ghent University, De Pintelaan 185, 2 Blok A, B-9000 Ghent, Belgium

${ }^{2}$ Research Foundation - Flanders, Egmontstraat 5, B-1000 Brussels, Belgium

${ }^{3}$ Unit for Preventive Nutrition, Department of Biosciences and Nutrition, Karolinska Institutet, Huddinge, Sweden

${ }^{4}$ Department of Medical Physiology, School of Medicine, Granada University, Granada, Spain

${ }^{5}$ Research Institute of Child Nutrition, Rheinische Friedrich-Wilhelms-University Bonn, Dortmund, Germany

${ }^{6}$ University of North Carolina, Chapel Hill, NC, USA

${ }^{7}$ Department of Nutrition and Dietetics, Harokopio University, Athens, Greece

${ }^{8}$ National Research Institute for Food and Nutrition (INRAN), Rome, Italy

${ }^{9}$ Department of Medical Physiology, School of Medicine, University of Granada, Granada, Spain

${ }^{10}$ Growth, Exercise, Nutrition and Development (GENUD) Research Group, School of Health Science (EUCS), University of Zaragoza, Domingo Miral s/ $n, 50009$ Zaragoza, Spain

${ }^{11}$ Inserm U995, IFR114, Faculté de Médecine, Université Lille 2, Lille, France

${ }^{12}$ Faculty of Physical Activity and Sport Sciences, Technical University of Madrid, Madrid, Spain

${ }^{13}$ Department of Nutrition and Food Science, University of Bonn, Bonn, Germany

${ }^{14}$ Division of Clinical Nutrition and Prevention, Department of Pediatrics, Medical University of Vienna, Vienna, Austria

${ }^{15}$ Preventive Medicine and Nutrition Clinic, School of Medicine, University of Crete, Crete, Greece

${ }^{16}$ Department of Physiology, University of Murcia, Murcia, Spain

${ }^{17}$ Department of Pediatrics, University of Pécs, Pécs, Hungary

${ }^{18}$ Department of Endocrinology, Ghent University Hospital, 9000 Ghent, Belgium

${ }^{19}$ Department of Consumer and Sensory Sciences, Campden BRI, Gloucestershire, UK

${ }^{20}$ School of Health, Care and Social Welfare, Märlardalens University, Västerås, Sweden

${ }^{21}$ Immunonutrition Research Group, Department of Metabolism and Nutrition, Spanish Council for Scientific Research (CSIC), Madrid, Spain

${ }^{22}$ Dietary Exposure Assessment Group, International Agency for Research on Cancer (IARC), Lyon, France

(Submitted 18 May 2012 - Final revision received 12 December 2012 - Accepted 12 December 2012 - First published online 14 March 2013)

\section{Abstract}

Evidence has grown supporting the role for short sleep duration as an independent risk factor for weight gain and obesity. The purpose of the present study was to examine the relationship between sleep duration and dietary quality in European adolescents. The sample consisted of 1522 adolescents (aged 12.5-17.5 years) participating in the European multi-centre cross-sectional 'Healthy Lifestyle in Europe by Nutrition in Adolescence' study. Sleep duration was estimated by a self-reported questionnaire. Dietary intake was assessed by two $24 \mathrm{~h}$

Abbreviations: DQI, Diet Quality Index; DQI-AM, Diet Quality Index for Adolescents with Meal index; FBDG, food-based dietary guidelines; HELENA, Healthy Lifestyle in Europe by Nutrition in Adolescence.

* Corresponding author: I. Huybrechts, fax +32 93324994, email inge.huybrechts@ugent.be

† See the Appendix for a full list of the HELENA study group members. 
recalls. The Diet Quality Index for Adolescents with Meal index (DQI-AM) was used to calculate overall dietary quality, considering the components dietary equilibrium, dietary diversity, dietary quality and a meal index. An average sleep duration of $\geq 9 \mathrm{~h}$ was classified as optimal, between 8 and $9 \mathrm{~h}$ as borderline insufficient and $<8 \mathrm{~h}$ as insufficient. Sleep duration and the DQI-AM score were positively associated $(\beta=0.027, r \quad 0 \cdot 130, P<0 \cdot 001)$. Adolescents with insufficient (62.05 (sD 14.18)) and borderline insufficient sleep (64.25 (SD 12.87)) scored lower on the DQI-AM than adolescents with an optimal sleep duration $(64 \cdot 57$ (SD $12 \cdot 39))(P<0 \cdot 001 ; P=0 \cdot 018)$. The present study demonstrated in European adolescents that short sleep duration was associated with a lower dietary quality. This supports the hypothesis that the health consequences of insufficient sleep may be mediated by the relationship of insufficient sleep to poor dietary quality.

\section{Key words: Sleep duration: Obesity: Adolescents: Diet: Diet Quality Index}

The increased prevalence in Western nations of overweight and obesity over the past half-century is of great public health concern. The situation is particularly alarming with regard to children and adolescents because of how overweight and obesity 'track' from childhood into adulthood ${ }^{(1)}$. It is typically assumed that obesity results from a positive energy balance attributable to excess energy intake and/or insufficient energy expenditure. However, attempts to prevent or manage obesity based on these traditional risk factors have been generally unsuccessful ${ }^{(2-5)}$.

This increased prevalence of obesity has been paralleled by a reduction in sleep duration ${ }^{(6)}$. Evidence to support this claim is scarce and conflicting. However, a recent systematic review concluded that there have been consistent rapid declines in the sleep duration of children and adolescents ${ }^{(7)}$. Experimental studies have shown that the need for sleep during adolescence (10-17 years) is estimated to be on average $9 \mathrm{~h}$ of sleep per night ${ }^{(8)}$. Surveys from the American National Sleep Foundation $^{(9)}$ in 2006 indicate that, on average, adolescents get about $7 \cdot 6 \mathrm{~h}$ of sleep on weekdays. Adolescents tend to have less sleep as they get older ${ }^{(9)}$, and there seems to be a prominent difference in sleep duration between weekdays and weekends among schoolchildren ${ }^{(10)}$.

Evidence has grown over the past decade in support of the theory that short sleep duration is a novel and independent risk factor for weight gain and obesity, especially in younger populations ${ }^{(11,12)}$. However, major study design and methodological limitations preclude definitive conclusions ${ }^{(11,13)}$, and the association between sleep duration and obesity in adolescence has been shown to differ by sex ${ }^{(14-17)}$. Potential mechanisms underlying the association between short sleep duration and obesity are still unclear. Based on experimental studies of sleep deprivation, different hypotheses have been formulated linking reduced sleep with obesity.

One of the strongest and most plausible hypotheses by which sleep deprivation might lead to weight gain is by increased or altered dietary intake ${ }^{(6)}$. Experimental and observational studies have shown that short sleep duration can disturb the homeostatic regulation of appetite through altering levels of several hormones including leptin, ghrelin, insulin and cortisol $^{(18-21)}$. Lack of sleep could also lead to weight gain and obesity by increasing the potential time available for eating ${ }^{(22)}$.

To our knowledge, only five observational studies have examined the relationship between sleep duration and nutritional intake in adolescents ${ }^{(23-27)}$, and none of them examined overall dietary quality using a dietary index. Foods and nutrients are not eaten in isolation and may have complicated interactions; also, nutrient bioavailability and absorption often depend on food preparation and eating patterns ${ }^{(28)}$. Therefore, most recent studies on diet and health attempt to address the multidimensional nature of the human diet ${ }^{(29)}$. Dietary indices are ideal for this purpose as they represent overall dietary quality and often show stronger correlations with the risk of disease than with individual nutrients or foods ${ }^{(30)}$.

The study of Garaulet et $a l^{(25)}$ found an association between short sleep duration and excess adiposity in European adolescents participating in the 'Healthy Lifestyle in Europe by Nutrition in Adolescence' (HELENA) study. They further elucidated whether physical activity, sedentary behaviours and/or inadequate food habits underlie this association. The relationship between sleep duration and food habits was, however, not exhaustively analysed and only nutritional data received from a FFQ were used, which are less detailed than $24 \mathrm{~h}$ recall data. The purpose of the present study was to further explore the association between sleep duration and dietary quality in the same sample of European adolescents. The present study contributes to the current knowledge on the relationship between sleep and dietary quality by using an index of diet quality and considering sex differences.

\section{Methods \\ Study design}

The HELENA cross-sectional study was established to broaden insight into the nutritional status and lifestyle of adolescents, and to explore the associations between diet and health. The study aimed to obtain standardised, reliable and comparable data from a random sample of European adolescents on a broad battery of relevant nutrition- and health-related parameters $^{(31,32)}$. Data collection took place from October 2006 until December 2007 in ten different European cities (Vienna, Ghent, Lille, Dortmund, Athens, Heraklion, Pécs, Rome, Zaragoza and Stockholm). A detailed description of the HELENA cross-sectional study sampling and recruitment approaches, standardisation and harmonisation processes, data collection, analysis strategies and quality control activities has been published elsewhere ${ }^{(33)}$. The study was performed following the ethical guidelines of the Declaration of Helsinki, the Good Clinical Practice rules and the legislation about clinical research in human subjects in each of the participating 
countries. The protocol was approved by the Human Research Review Committees of the centres involved ${ }^{(34)}$.

\section{Subjects}

Adolescents, aged 12.5-17.5 years, were recruited from randomly selected schools. After receiving complete information about the aims and methods of the study, all adolescents gave assent to participate in the study and their parents or guardians provided informed written consent. Participants were excluded a posteriori from the database if they met one or more of the exclusion criteria: $<12.5$ or $>17.5$ years old; missing weight and/or height data; participating simultaneously in another clinical trial; having had an acute infection less than 1 week before the measurement ${ }^{(33)}$. The total eligible HELENA study population consisted of 3528 adolescents (52.3\% girls). Participants from Heraklion and Pécs were excluded from the analyses in the present study as no nutrient intake information could be calculated for these cities due to logistical problems. Therefore, eight HELENA centres were included in the study. In the present study, only adolescents who provided two non-consecutive $24 \mathrm{~h}$ recalls were included in the analyses, resulting in 2330 subjects. Furthermore, under-reporters were excluded from all analyses, resulting in a sample of 1804 adolescents. BMR was calculated from age-specific FAO/WHO/United Nations University equations ${ }^{(35)}$. Under-reporting was considered when the ratio of energy intake:estimated BMR was $<0.96$, as proposed by Black ${ }^{(36)}$. For the purpose of the present study, only adolescents with valid data on sleep duration, Diet Quality Index for Adolescents with Meal index (DQI-AM), body fat percentage, Tanner stage, physical activity and maternal educational level were included in the analyses, resulting in 1522 (53.4\% girls) valid cases (see Fig. 1). Characteristics of the included group of adolescents were compared with those of the excluded group of adolescents (data not shown). The included group had a longer sleep duration $(8.13 v .7 .97 \mathrm{~h} /$ night, $P=0.001)$, a lower BMI $z$-score $(0.25 v .0 .68, P<0.001)$, a lower body fat percentage $(21.86 v .24 .97 \%, P<0.001)$ and a higher DQI-AM score $(63.67 v .60 .34, P<0.001)$ than the excluded group. The included adolescents had a higher percentage of mothers with a higher secondary education or higher education/higher degree (69.4 v. 61.3\%, $P<0.001)$ than the excluded group, and adolescents were less frequently categorised in a higher Tanner stage (stage 4 or $5,67.8 \mathrm{v}$. $75.0 \%, P<0.001)$. No differences in age, sex and physical activity were observed.

\section{Dietary intake and diet quality}

Following recommendations of the 'European Food Consumption Survey Method' project, two non-consecutive $24 \mathrm{~h}$ recalls were completed by the adolescents ${ }^{(37)}$. The dietary intake assessment was performed by a computer-based tool for self-reported $24 \mathrm{~h}$ recalls, the HELENA Dietary Intake Assessment Tool, based on a previous version developed for Flemish adolescents, called Young Adolescents' Nutrition Assessment on Computer ${ }^{(38)}$. This tool has been proven to provide a valid measurement of food consumption compared with an interview by a dietitian ${ }^{(39)}$. Food intake refers to the day before the administration of the recall and is divided into six meal occasions. For each occasion, the user is invited to select all the consumed food items and beverages from a standardised food list. Information on quantities is gathered by the use of household measurements or pictures

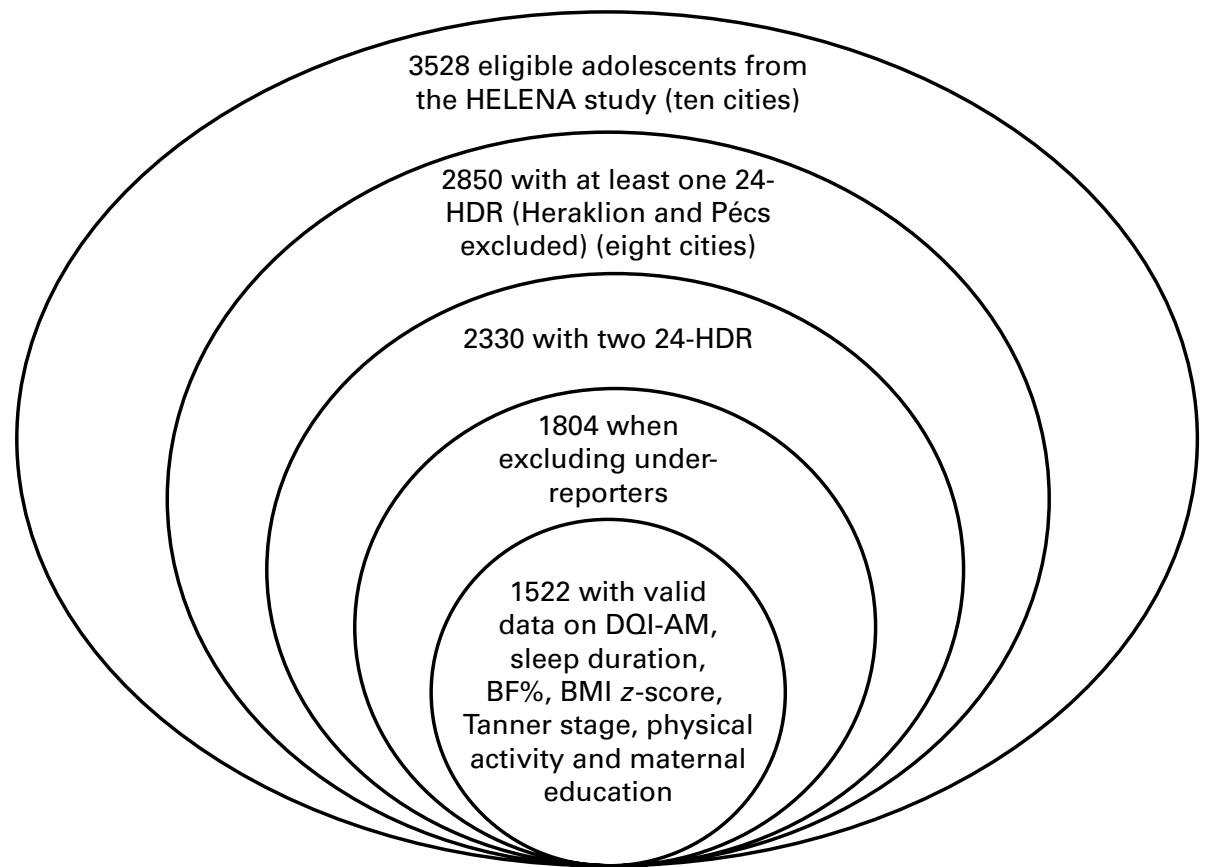

Fig. 1. Flow chart illustrating the exclusion procedure for the study population of adolescents included in the present study. HELENA, Healthy Lifestyle in Europe by Nutrition in Adolescence; 24-HDR, $24 \mathrm{~h}$ dietary recall; DQI-AM, Diet Quality Index for Adolescents with Meal index; BF\%, body fat percentage. 
of portion sizes. The adolescents completed the programme autonomously in a computer classroom where fieldworkers could give assistance if necessary ${ }^{(39)}$. The two $24 \mathrm{~h}$ recalls comprised weekdays and weekend days, but not necessarily a weekday and weekend day for each individual. Because all $24 \mathrm{~h}$ recalls took place during the week (in the classroom), no information was available on the dietary intake of Fridays and Saturdays.

To measure diet quality, the DQI-AM was used. This is an adapted version of a previously validated $\mathrm{DQI}^{(40)}$, which was developed for assessing the compliance of preschool children with the Flemish food-based dietary guidelines (FBDG) ${ }^{(41)}$. Unpublished analyses of data collected on adolescents showed that the Diet Quality Index for Adolescents scores were positively associated with nutrient-dense food items (e.g. fruits and vegetables) and inversely associated with energy-dense and low-nutritious food. The Diet Quality Index for Adolescents was also positively related to the intake of water, fibre and most minerals and vitamins and had a positive association with vitamin $\mathrm{D}$, vitamin $\mathrm{B}_{12}$ and $n$ - 3 fatty acid serum levels. These results indicate a good validity of the Diet Quality Index for Adolescents in adolescents ${ }^{(42)}$.

The intake of foods (provided by the $24 \mathrm{~h}$ recalls) was divided into nine recommended food groups and two nonrecommended food groups based on the Flemish FBDG $^{(41)}$ : (1) water; (2) bread and cereal; (3) grains and potatoes; (4) fruits; (5) vegetables; (6) milk products; (7) cheese; (8) meat, fish, eggs and substitutes; (9) fat and oils; (10) low-nutrient, energy-dense foods (e.g. chocolate); (11) low-nutrient, energy-dense drinks (e.g. carbonated soft drinks). For each of these food groups, a range of recommended daily intakes specifically for adolescents is provided by the Flemish FBDG. These ranges were based upon the nutrient recommendations of the Belgian Health Council ${ }^{(43)}$ and the $\mathrm{WHO}^{(44)}$, combined with data on habitual dietary intake in the Belgian population. Because the Flemish FBDG are very similar to dietary guidelines in other countries and to the Countrywide Integrated Non-Communicable Disease Intervention pyramid (from the Countrywide Integrated Non-Communicable Disease Intervention programme) developed by the $\mathrm{WHO}^{(45)}$, the index is applicable for a European population.

The DQI-AM consists of four pillars based on the principles of a healthy diet as provided in the Flemish FBDG $^{(41)}$ : dietary quality; dietary diversity; dietary equilibrium (adequacy and moderation); a meal index. The dietary quality indicates whether an individual makes optimal food quality choices within each food group. In the Flemish FBDG, foods are categorised into a 'preference group' (e.g. fresh fruit, fish), a 'moderation group' (e.g. white bread, minced meat) and a 'rest group' including low-nutrient, energy-dense foods (e.g. soft drinks, sweet snacks). To calculate the dietary quality score, the daily portion size of foods from the preference group was multiplied by a factor ' 1 ', foods categorised as moderate with a factor ' 0 ' and those in the rest group with a factor ' -1 '. These values were summed and divided by the total sum of food quantities eaten per $d$ and multiplied by 100 . Dietary diversity expresses the degree of variation in the diet and indicates whether a participant consumes at least one serving of food per $\mathrm{d}$ from each of the nine recommended food groups. The dietary diversity score was computed by dividing the number of food groups from which on average at least one serving was consumed by nine (the total number of the recommended food groups). Dietary equilibrium indicates to what extent the consumed portion sizes of the different food groups correspond with the recommended daily intakes. It results from the difference between the adequacy score (the percentage of the minimum recommended intake for each of the main food groups) and the dietary excess score (expressing the percentage of intake exceeding the upper level of recommendation). Finally, the meal index reflects the frequency of consumption of meals (which should include at least three main courses, as breakfast, lunch or dinner). The three components, dietary diversity, dietary equilibrium and the meal index, can range between 0 and $100 \%$, while the dietary quality component can range between -100 and $100 \%$. To compute the overall DQI-AM, the score is the mean of the four pillars and ranges from -25 to $100 \%$, with higher scores indicating a higher diet quality. More detailed information on the technical aspects has been provided elsewhere ${ }^{(40)}$.

\section{Anthropometric data}

The protocol used to collect anthropometric data has been described previously ${ }^{(46)}$. Measurements were done while participants were barefoot and in underwear. Weight was measured to the nearest $0 \cdot 1 \mathrm{~kg}$ using electronic scales (Type SECA 861 MWS Ltd, Scalesmart). Height was measured to the nearest $0 \cdot 1 \mathrm{~cm}$ with the head aligned in the Frankfort plane using a telescopic height-measuring instrument (Type SECA 225). BMI was calculated as body weight in kg divided by the square of height in $\mathrm{m}$. In addition, BMI was adjusted for age and sex to give a BMI $z$-score using the British 1990 Growth Reference Data from the Child Growth Foundation ${ }^{(47)}$. A set of skinfold thicknesses were measured three (consecutive) times on the left side of the body, with a Holtain caliper (to the nearest $0.2 \mathrm{~mm}$ ). Body fat percentage was calculated from the triceps and subscapular skinfolds using the Slaughter formulae ${ }^{(48)}$, which appears to be the most suitable for use in adolescents ${ }^{(49)}$. Pubertal status (stages I-V) was assessed by a medical doctor according to the scale developed by Tanner \& Whitehouse ${ }^{(50)}$, based on breast development and pubic hair status in females and genital and pubic hair development in males.

\section{Sleep duration}

Habitual sleep duration was estimated using a self-reported questionnaire. The question 'How many hours (and minutes) do you usually sleep during weekdays and during weekend days?' was asked. The average sleep duration was calculated as:

$$
\text { Average sleep duration }=((\text { hours weekdays } \times 5)
$$

$$
+(\text { hours weekend days } \times 2)) / 7 \text {. }
$$

Sleep on weekdays and weekend days were not analysed separately because there was no information on dietary 
intake on days with a 'weekend' night (Fridays or Saturdays). Sleep duration during the week $(8 \cdot 11$ (SD 1.10) h) was significantly shorter than during the weekend ( 8.18 (SD 1.34) h) $(P<0 \cdot 001)$. The difference was, however, very small $(0.07 \mathrm{~h}$ or $4 \mathrm{~min})$. Weekday and weekend day sleep durations were positively associated ( $r 0 \cdot 846, P<0 \cdot 001)$.

In addition to analysing sleep duration as a continuous variable, sleep duration was stratified into three categories: insufficient sleep duration ( $<8 \mathrm{~h}$ of sleep per night), borderline insufficient sleep duration (between 8 and $9 \mathrm{~h}$ of sleep per night) and optimal sleep duration ( $\geq 9 \mathrm{~h}$ of sleep per night), according to the definition of the American National Sleep Foundation $^{(9)}$.

\section{Socio-economic status and physical activity}

A self-reported questionnaire was used to collect data on living conditions, family structure, employment status, occupation and education level of both parents ${ }^{(51)}$. Maternal education level (lower education, higher secondary education and university education) was chosen as a potential confounding factor for the habitual diet quality of the adolescents.

A measure of physical activity was obtained by the International Physical Activity Questionnaire for Adolescents. The validity of this questionnaire has been published previously $^{(52)}$. Reported activities were classified into low, moderate and vigorous activity according to the guidelines for data processing and analyses of the International Physical Activity Questionnaire (http://www.ipaq.ki.se). Total time spent on moderate and vigorous activity was summed and truncated in order to avoid overestimations ${ }^{(53)}$.

\section{Statistical analyses}

Analyses were performed using SPSS software (PASW Statistics 18.0). A $P$ value $<0.05$ was considered as significant. The normality of continuous variables was tested using the Kolmogorov-Smirnov test and by visually checking histograms. Variables that were not normally distributed were either log-transformed or square root-transformed. Means and standard deviations or proportions of the adolescents' characteristics were calculated, and differences in these characteristics between the three sleep duration categories were examined using a one-way ANOVA for continuous variables and a $\chi^{2}$ test for categorical variables. An independent $t$ test was used to compare the characteristics between the included and excluded adolescents. To compare the average sleep duration during weekdays and weekend days, a paired $t$ test was used. A multilevel linear regression analysis (mixed model) with city of origin and school as cluster units was used to examine the relationship between sleep duration (independent variable) and diet quality (dependent variable). Partial Pearson's correlation coefficients were calculated to determine the associations between sleep duration and diet quality. A mixed-model ANCOVA was used to compare diet quality between the groups of adolescents with the different sleep durations (insufficient, borderline insufficient and optimal sleep duration). Analyses were adjusted for relevant confounding factors (sex, Tanner stage, maternal educational level, body fat percentage and physical activity). Analyses were not stratified for sex because no sex interactions were found for diet quality in the regression model.

\section{Results}

In total, 1522 adolescents were included in the present study (812 girls). Table 1 gives a description of the study population, stratified by sleep duration category. The mean age of the total study sample was 14.7 years. Of the adolescents, 92\% were categorised into a Tanner stage 3 or higher and the largest proportion of mothers had a higher education or university degree. For several characteristics, a statistically significant difference was found between the sleep duration categories. Adolescents with insufficient sleep or borderline insufficient sleep were significantly older $(P<0.001)$ and were more frequently categorised into a higher Tanner stage (stage 4 or 5 , $P<0.001)$ than adolescents with an optimal sleep duration. Adolescents with insufficient sleep had a significantly higher BMI $z$-score and body fat percentage than their peers with an optimal sleep duration. Adolescents with (borderline) insufficient sleep also spent less time in moderate-to-vigorous physical activity and had a lower mean average sleep duration than adolescents with an optimal sleep duration $(P<0 \cdot 001)$.

The multilevel analysis (Table 2 ) showed a significant negative association between the average sleep duration and the DQI-AM score $(\beta=0.027, r \quad 0 \cdot 130, P<0 \cdot 001)$. No significant associations were found between the average sleep duration and the four subscores of the DQI-AM.

Differences in diet quality in adolescents with an insufficient sleep duration $(<8 \mathrm{~h})$, a borderline insufficient sleep duration (between 8 and $9 \mathrm{~h}$ ) and an optimal sleep duration ( $\geq 9 \mathrm{~h}$ ), after adjusting for sex, Tanner stage, body fat percentage, maternal education and physical activity, are presented in Table 3. Adolescents with an insufficient sleep duration (62.05 (SD 14.18)) or a borderline insufficient sleep duration (64.25 (SD 12.87)) scored lower on the DQI-AM than those with an optimal sleep duration (64.57 (SD 12.39)) $(P<0.001$; $P=0 \cdot 018)$. No significant differences were found in the scores of the four components of the DQI-AM between the three sleep duration categories. Adolescents with a borderline insufficient sleep duration scored lower on the meal index component than adolescents with an optimal sleep duration; however, this was only borderline significant $(P=0.062)$.

\section{Discussion}

Most observational studies investigating the relationship between sleep duration and dietary intake have analysed the intake of individual nutrients and energy intake. The present study used a Diet Quality Index, which is a valuable tool to assess overall dietary quality or adherence to dietary guidelines. The study investigated the relationship between sleep duration and the DQI-AM. Sleep duration was positively related to the DQI-AM score. This association could also be observed when using sleep duration categories: adolescents with an optimal 
Table 1. Characteristics of the study population, stratified by sleep duration (Mean values and standard deviations; number of participants and percentages)

\begin{tabular}{|c|c|c|c|c|c|c|c|c|c|}
\hline & & & \multicolumn{6}{|c|}{ Sleep duration categories } & \multirow[b]{3}{*}{$P \dagger$} \\
\hline & \multicolumn{2}{|c|}{$\begin{array}{l}\text { Total sample } \\
\text { (n 1522) }\end{array}$} & \multicolumn{2}{|c|}{$\begin{array}{c}\text { Insufficient } \\
(<8 \mathrm{~h} / \text { night, } \\
n 464)\end{array}$} & \multicolumn{2}{|c|}{$\begin{array}{c}\text { Borderline } \\
\text { insufficient } \\
\text { (8-9h/night, } \\
n 612)\end{array}$} & \multicolumn{2}{|c|}{$\begin{array}{c}\text { Optimal } \\
(\geq 9 \mathrm{~h} / \mathrm{night} \\
n 446)\end{array}$} & \\
\hline & $n$ & $\%$ & $n$ & $\%$ & $n$ & $\%$ & $n$ & $\%$ & \\
\hline \multicolumn{10}{|l|}{ Age (years) } \\
\hline Mean & 14.71 & & $15 \cdot 16^{*}$ & & $14 \cdot 75^{\star}$ & & $14 \cdot 18$ & & $<0.001 \ddagger$ \\
\hline SD & 1.23 & & $1 \cdot 18$ & & 1.21 & & $1 \cdot 10$ & & \\
\hline \multicolumn{10}{|l|}{ Sex } \\
\hline Male & 710 & $46 \cdot 6$ & 205 & $44 \cdot 2$ & 293 & $47 \cdot 9$ & 212 & 47.5 & 0.439 \\
\hline Female & 812 & 53.4 & 259 & $55 \cdot 8$ & 319 & $52 \cdot 1$ & 234 & $52 \cdot 5$ & \\
\hline \multicolumn{10}{|l|}{ Tanner stage } \\
\hline Stage 1 & 6 & 0.4 & 0 & 0 & 2 & 0.3 & 4 & 0.9 & $<0.001 \ddagger$ \\
\hline Stage 2 & 117 & $7 \cdot 7$ & 19 & $4 \cdot 1$ & 44 & $7 \cdot 2$ & 54 & $12 \cdot 1$ & \\
\hline Stage 3 & 368 & $24 \cdot 2$ & 91 & $19 \cdot 6$ & 155 & $25 \cdot 3$ & 122 & 27.4 & \\
\hline Stage 4 & 639 & $42 \cdot 0$ & 233 & $50 \cdot 2$ & 229 & 37.4 & 177 & $39 \cdot 7$ & \\
\hline Stage 5 & 392 & $25 \cdot 8$ & 121 & $26 \cdot 1$ & 182 & $29 \cdot 7$ & 89 & $20 \cdot 0$ & \\
\hline \multicolumn{10}{|l|}{ Maternal education } \\
\hline Lower education & 105 & 6.9 & 38 & 8.2 & 38 & $6 \cdot 2$ & 29 & $6 \cdot 5$ & 0.223 \\
\hline Lower secondary education & 360 & 23.7 & 101 & $21 \cdot 8$ & 139 & $22 \cdot 7$ & 120 & $26 \cdot 9$ & \\
\hline Higher secondary education & 489 & $32 \cdot 1$ & 161 & $34 \cdot 7$ & 189 & $30 \cdot 9$ & 139 & $31 \cdot 2$ & \\
\hline Higher education or university degree & 568 & $37 \cdot 3$ & 164 & $35 \cdot 3$ & 246 & $40 \cdot 2$ & 158 & $35 \cdot 4$ & \\
\hline \multicolumn{10}{|l|}{ BMI (z-score) } \\
\hline Mean & 0.25 & & $0.34^{*}$ & & 0.25 & & 0.17 & & $0.042 \ddagger$ \\
\hline SD & 1.05 & & 0.96 & & 1.08 & & $1 \cdot 11$ & & \\
\hline \multicolumn{10}{|l|}{ Body fat (\%) } \\
\hline Mean & $21 \cdot 86$ & & $22 \cdot 33^{*}$ & & 21.96 & & $21 \cdot 22$ & & $0.039 \ddagger$ \\
\hline SD & 8.62 & & 7.97 & & 8.90 & & 8.84 & & \\
\hline \multicolumn{10}{|l|}{ MVPA (min/week) } \\
\hline Mean & $700 \cdot 79$ & & $626 \cdot 64^{*}$ & & $706 \cdot 21^{*}$ & & $770 \cdot 47$ & & $<0.001 \ddagger$ \\
\hline SD & 557.56 & & $535 \cdot 26$ & & $575 \cdot 34$ & & $547 \cdot 12$ & & \\
\hline \multicolumn{10}{|l|}{ Sleep duration (h/night) } \\
\hline Mean & $8 \cdot 13$ & & $6 \cdot 86^{*}$ & & $8 \cdot 14^{*}$ & & 9.43 & & $<0.001 \ddagger$ \\
\hline SD & 1.13 & & 0.62 & & 0.22 & & 0.72 & & \\
\hline
\end{tabular}

MVPA, moderate-to-vigorous physical activity.

${ }^{*}$ Mean value was significantly different from that of the optimal sleep duration category $(P<0.05$; pairwise comparisons: adjustment for multiple comparisons with least significant difference).

$\dagger P$ value of one-way ANOVA for continuous variables and $\chi^{2}$ test for categorical variables.

$\ddagger P$ values were significant $(P<0.05)$.

sleep duration had a better DQI-AM score than those with an insufficient or borderline sleep duration. However, the clinical significance of these differences in DQI scores should be further investigated in future research studies.

Table 2. Multilevel analysis, with cities and schools as cluster units, examining the associations between the average sleep duration (independent variable) and the Diet Quality Index for Adolescents with Meal index (DQI-AM) scores (dependent variable)

( $\beta$ Coefficients and $95 \%$ confidence intervals)

\begin{tabular}{lrrrc}
\hline & \multicolumn{1}{c}{$r$} & \multicolumn{1}{c}{$95 \% \mathrm{Cl}$} & $P^{\star}$ \\
\hline DQI-AM & 0.027 & 0.130 & $0.018,0.037$ & $<0.001 \dagger$ \\
Dietary quality & 1.488 & 0.037 & $-0.357,3.334$ & 0.114 \\
Dietary diversity & -0.191 & -0.007 & $-0.917,0.535$ & 0.606 \\
Dietary equilibrium & 0.046 & 0.009 & $-0.500,0.590$ & 0.869 \\
Meal index & 0.422 & 0.028 & $-0.301,1.145$ & 0.252
\end{tabular}

$\beta$, Estimate (unstandardised regression coefficient); $r$, partial Pearson's correlation coefficient.

${ }^{*} P$ value adjusted for sex, Tanner stage, maternal educational level, body fat percentage and moderate-to-vigorous physical activity.

$\dagger P$ value was significant $(P<0.05)$.
In line with the results of the present study, the observational study of Hitze et al. ${ }^{(26)}$ found in children and adolescents (6-20 years) that sleep duration was determined by a higher nutritional quality score, but only in girls. A higher nutritional score was characterised by high consumptions of healthy items (whole-meal products, milk products, fruits, vegetables and potatoes, and fish) and low consumptions of risk-related items (white bread, meat products, soft drinks, fast food and sweets). Fast food (girls) and soft drinks (boys) were more often consumed by 'short' sleepers, whereas for sweets, the opposite was true $(\text { girls })^{(26)}$. The study of Garaulet et al. ${ }^{(25)}$ in the same European sample found that the proportion of adolescents who had an adequate frequency of eating fruit, vegetables, fish, skimmed milk, breakfast cereals or crisps was lower for those who on average slept less than $8 \mathrm{~h}$. They also found an inverse correlation between the average sleep duration per $\mathrm{d}$ and the frequency of eating foods such as pizza, hamburgers, pasta dishes and pasta snack products ${ }^{(25)}$. These findings already suggested a lower dietary quality in adolescents with 
Table 3. Multilevel ANCOVA of dietary quality (Diet Quality Index for Adolescents with Meal index; DQI-AM) according to sleep duration (with cities and schools as cluster units)

(Mean values and standard deviations)

\begin{tabular}{|c|c|c|c|c|c|c|c|c|}
\hline & \multicolumn{8}{|c|}{ Sleep duration } \\
\hline & \multicolumn{3}{|c|}{ Insufficient $(<8 \mathrm{~h} /$ night, $n$ 464) } & \multicolumn{3}{|c|}{$\begin{array}{l}\text { Borderline insufficient } \\
(8-9 \text { h/night, } n 612)\end{array}$} & \multicolumn{2}{|c|}{$\begin{array}{c}\text { Optimal } \\
(\geq 9 \mathrm{~h} / \mathrm{night} \\
n \text { 446) }\end{array}$} \\
\hline & Mean & SD & $P^{\star}$ & Mean & SD & $P^{*}$ & Mean & SD \\
\hline DQI-AM & $62 \cdot 05$ & $14 \cdot 18$ & $<0.001 \dagger$ & 64.25 & $12 \cdot 87$ & $0.018 \dagger$ & 64.57 & $12 \cdot 39$ \\
\hline Dietary quality & $40 \cdot 26$ & 35.05 & 0.236 & 43.19 & 34.61 & 0.950 & $42 \cdot 14$ & 37.95 \\
\hline Dietary diversity & 74.42 & 14.42 & 0.118 & 74.05 & 14.97 & 0.202 & 72.92 & 14.07 \\
\hline Dietary equilibrium & 40.58 & $10 \cdot 47$ & 0.885 & $41 \cdot 34$ & $10 \cdot 08$ & $0 \cdot 171$ & $40 \cdot 20$ & $10 \cdot 60$ \\
\hline Meal index & 91.67 & 14.28 & 0.399 & $90 \cdot 65$ & $13 \cdot 86$ & 0.062 & $92 \cdot 17$ & $13 \cdot 30$ \\
\hline
\end{tabular}

a short sleep duration. In the cross-sectional study of Weiss et al. $^{(24)}$ in adolescents, shorter sleep duration was also associated with an increased risk of daily consuming $1987 \mathrm{~kJ}$ ( $475 \mathrm{kcal})$ or more from snacks (unadjusted analyses).

Several hypotheses can account for the observed relationship between sleep duration and an altered dietary quality in the present study. Experimental and observational studies have shown that short sleep duration is associated with a disturbance of satiety hormones, i.e. decreased leptin levels and increased ghrelin levels, which can lead to an increase in hunger and appetite ${ }^{(18-21,27)}$. The experimental study of Spiegel et al. ${ }^{(18)}$, in which sleep was restricted under laboratory conditions, observed an increase in appetite for energydense foods with a high carbohydrate content including sweets (such as cake, candy, cookies, ice cream and pastry), salty snacks (such as chips, salty nuts, pickles and olives) and starchy foods (such as bread, pasta, cereal and potatoes). Appetite for fruits, vegetables and high-protein foods was less affected. This could explain a lower diet quality when sleep is restricted. Another explanation could be that sleeping short hours in an obesity-promoting environment, where food is highly palatable and readily available, may facilitate the excessive consumption of unhealthy foods, especially if most of this time is spent in sedentary activities where snacking simultaneously is common, such as watching television or spending time on the computer ${ }^{(6,22)}$. In the experimental study of Nedeltcheva et al. ${ }^{(54)}$, sleep restriction in adults, with an ad libitum access to palatable food, resulted in increased consumption of energy from snacks, with a higher carbohydrate content, particularly during the period from 19.00 to 07.00 hours. Tiredness may also affect dietary habits. People who are tired may seek fast-release, high-energy foods to compensate for perceived low energy levels ${ }^{(55)}$. Inadequate sleep has been shown to be associated with feeling tired, stressed and pessimistic ${ }^{(56)}$, emotional states that could lessen one's resolve to follow dietary regimens ${ }^{(57)}$. Furthermore, sleep deprivation has been found to hamper attention and impulse control and can delay gratification, thus leading to increased hedonistic eating ${ }^{(6,58)}$. A recent study found that restricted sleep resulted in changes in neuronal activity when exposed to food stimuli, which affected brain regions that have been associated with motivation and desire. This might indicate an increased propensity to seek food in individuals who are not getting enough sleep ${ }^{(59)}$. The study of Landis et al. ${ }^{(23)}$ found that daytime sleep (which was associated with decreased nocturnal sleep) was positively associated with food cravings (cravings for carbohydrate-starch and high-fat foods).

\section{Strengths and limitations}

The major strength of the present study is the large sample of adolescents from eight cities across Europe and the highly standardised procedures used. To our knowledge, this is the first study to investigate the association between sleep and dietary quality in adolescents, using a Diet Quality Index. Nevertheless, the present study has also some limitations. First, the cross-sectional design of the study prevents us from finding a causal direction between sleep duration and dietary quality. It could be possible that dietary intake influenced sleep duration, which was recently demonstrated in young children by Diethelm et al. ${ }^{(60)}$. Second, data on physical activity, sleeping behaviours and dietary intake were derived from self-reported questionnaires and are thus subjective in nature. A possible reporting bias in these parameters could lead to an overestimate of the correlations. Health-conscious adolescents may be pleased to report healthy food habits and long hours of sleeping, while 'rebel' adolescents might be pleased to show that they go to bed late in the evening and never eat their fruit and vegetables. Nevertheless, all the aforementioned questionnaires have been pilot tested and validated $^{(39,52,61)}$. Moreover, previous studies found an agreement between self-reported sleep duration and sleep duration measured by actigraphy ${ }^{(62-64)}$. Another limitation of the study is the fact that the $24 \mathrm{~h}$ recall data did not include any information about the adolescents' diet on Fridays and Saturdays since the $24 \mathrm{~h}$ recalls were all completed during school days (about the dietary intake of the previous day). Sleep duration on these 'weekend' nights was included in the average sleep duration. However, the difference between sleep duration on weekdays and weekend days was, although statistically 
significant, very small. Another possible limitation is that the DQI-AM used in the present study was based on the Flemish dietary guidelines. However, these guidelines were considered appropriate to apply on a European population because only minor differences were found in comparison with the other European dietary guidelines. A difference in sleep duration between different countries could not be made because the adolescents from one city were not representative for that country. Finally, the study observed significant differences in several variables between the included and excluded adolescents, including sleep duration, body composition and DQI-AM scores. This selection bias might slightly have affected the observed sleep duration and the DQI-AM, but unlikely have led to a spurious correlation between sleep duration and dietary quality.

\section{Conclusion}

The present study demonstrated that, in European adolescents, reported short sleep duration is associated with a lower quality of the reported diet. These findings support the hypothesis of an altered dietary quality in the presence of sleep restriction, possibly leading to obesity and other diet-associated health problems. Further research, with objective measurements and prospective or experimental study designs, is needed to better define the relationship between sleep restriction, diet and health.

\section{Acknowledgements}

The HELENA study was supported by the European Community Sixth RTD Framework Programme (contract FOODCT-2005-007034). The content of this article reflects only the authors' views and the European Community is not liable for any use that may be made of the information contained therein. The present study was also supported by the Research Foundation - Flanders (grant no. 1.1.746.09.N.01 to T. D. V.). The authors' contributions were as follows: L. A. M. coordinated the HELENA project at the international level. L. A. M., D. M., K. W., Y. M. and S. D. H. were involved in the design of the HELENA project and locally coordinated the HELENA project. T. D. V. and E. P. organised the fieldwork and performed the data collection locally. I. H. was responsible for the database management and designed the DQI-AM. S. B., I. H. and N. M. were involved in the manuscript drafting and statistical analysis. T. D. V., E. P., M. C.-G., K. D., B. G., E. G., Y. M., C. L., F. B. O., L. A. M., F. G., M. G.-G., K. W., A. K., M. G., J.-M. K., C. C. G., L. H., M. S. and A. M. assisted in the interpretation of the results. All authors reviewed the manuscript, gave input and made significant improvements.

All authors indicate no financial conflict of interest.

The content of this paper reflects only the authors' views and the rest of HELENA study members are not responsible for it.

\section{References}

1. Singh AS, Mulder C, Twisk JW, et al. (2008) Tracking of childhood overweight into adulthood: a systematic review of the literature. Obes Rev 9, 474-488.
2. Lemmens VE, Oenema A, Klepp KI, et al. (2008) A systematic review of the evidence regarding efficacy of obesity prevention interventions among adults. Obes Rev 9, 446-455.

3. Astrup A, Grunwald GK, Melanson EL, et al. (2000) The role of low-fat diets in body weight control: a meta-analysis of $a d$ libitum dietary intervention studies. Int J Obes Relat Metab Disord 24, 1545-1552.

4. Pirozzo S, Summerbell C, Cameron C, et al. (2003) Should we recommend low-fat diets for obesity? Obes Rev 4, 83-90.

5. Shaw K, Gennat H, O'Rourke P, et al. (2006) Exercise for overweight or obesity. The Cochrane Database Systematic Reviews, CD003817.

6. Patel SR (2009) Reduced sleep as an obesity risk factor. Obes Rev 10, 61-68.

7. Matricciani L, Olds T \& Petkov J (2012) In search of lost sleep: secular trends in the sleep time of school-aged children and adolescents. Sleep Med Rev 16, 203-211.

8. Carskadon MA \& Acebo C (2002) Regulation of sleepiness in adolescents: update, insights, and speculation. Sleep $\mathbf{2 5}$, 606-614.

9. National Sleep Foundation (2006) 'Sleep in America' Poll. Washington, DC: National Sleep Foundation.

10. Wing YK, Li SX, Li AM, et al. (2009) The effect of weekend and holiday sleep compensation on childhood overweight and obesity. Pediatrics 124, e994-e1000.

11. Patel SR \& Hu FB (2008) Short sleep duration and weight gain: a systematic review. Obesity (Silver Spring) 16, $643-653$.

12. Van Cauter E \& Knutson KL (2008) Sleep and the epidemic of obesity in children and adults. Eur J Endocrinol 159, 59-66.

13. Grandner MA, Patel NP, Gehrman PR, et al. (2010) Problems associated with short sleep: bridging the gap between laboratory and epidemiological studies. Sleep Med Rev 14, $239-247$.

14. Chen X, Beydoun MA \& Wang Y (2008) Is sleep duration associated with childhood obesity? A systematic review and meta-analysis. Obesity (Silver Spring) 16, 265-274.

15. Knutson KL (2005) Sex differences in the association between sleep and body mass index in adolescents. J Pediatr 147, 830-834.

16. Eisenmann JC, Ekkekakis P \& Holmes M (2006) Sleep duration and overweight among Australian children and adolescents. Acta Paediatr 95, 956-963.

17. Yu Y, Lu BS, Wang B, et al. (2007) Short sleep duration and adiposity in Chinese adolescents. Sleep 30, 1688-1697.

18. Spiegel K, Tasali E, Penev P, et al. (2004) Brief communication: sleep curtailment in healthy young men is associated with decreased leptin levels, elevated ghrelin levels, and increased hunger and appetite. Ann Intern Med 141, $846-850$.

19. Spiegel K, Leproult R, L'hermite-Baleriaux M, et al. (2004) Leptin levels are dependent on sleep duration: relationships with sympathovagal balance, carbohydrate regulation, cortisol, and thyrotropin. J Clin Endocrinol Metab 89, 5762-5771.

20. Chaput JP, Despres JP, Bouchard C, et al. (2007) Short sleep duration is associated with reduced leptin levels and increased adiposity: results from the Quebec family study. Obesity (Silver Spring) 15, 253-261.

21. Taheri S, Lin L, Austin D, et al. (2004) Short sleep duration is associated with reduced leptin, elevated ghrelin, and increased body mass index. PLoS Med 1, e62.

22. Chaput JP, Sjodin AM, Astrup A, et al. (2010) Risk factors for adult overweight and obesity: the importance of looking beyond the 'big two'. Obes Facts 3, 320-327. 
23. Landis AM, Parker KP \& Dunbar SB (2009) Sleep, hunger, satiety, food cravings, and caloric intake in adolescents. J Nurs Scholarsh 41, 115-123.

24. Weiss A, Xu F, Storfer-Isser A, et al. (2010) The association of sleep duration with adolescents' fat and carbohydrate consumption. Sleep 33, 1201-1209.

25. Garaulet M, Ortega FB, Ruiz JR, et al. (2011) Short sleep duration is associated with increased obesity markers in European adolescents: effect of physical activity and dietary habits. The HELENA study. Int J Obes (Lond) 35, 1308-1317.

26. Hitze B, Bosy-Westphal A, Bielfeldt F, et al. (2009) Determinants and impact of sleep duration in children and adolescents: data of the Kiel Obesity Prevention Study. Eur J Clin Nutr 63, 739-746.

27. Al-Disi D, Al-Daghri N, Khanam L, et al. (2010) Subjective sleep duration and quality influence diet composition and circulating adipocytokines and ghrelin levels in teen-age girls. Endocr J 57, 915-923.

28. Hu FB (2002) Dietary pattern analysis: a new direction in nutritional epidemiology. Curr Opin Lipidol 13, 3-9.

29. Waijers PM, Feskens EJ \& Ocke MC (2007) A critical review of predefined diet quality scores. Br J Nutr 97, 219-231.

30. Kant AK (1996) Indexes of overall diet quality: a review. J Am Diet Assoc 96, 785-791.

31. De Henauw S, Gottrand F, De Bourdeaudhuij I, et al. (2007) Nutritional status and lifestyles of adolescents from a public health perspective. The HELENA Project - Healthy Lifestyle in Europe by Nutrition in Adolescence. J Public Health 15 , 187-197.

32. Moreno LA, Gonzalez-Gross M, Kersting M, et al. (2008) Assessing, understanding and modifying nutritional status, eating habits and physical activity in European adolescents: the HELENA (Healthy Lifestyle in Europe by Nutrition in Adolescence) Study. Public Health Nutr 11, 288-299.

33. Moreno LA, De Henauw S, Gonzalez-Gross M, et al. (2008) Design and implementation of the Healthy Lifestyle in Europe by Nutrition in Adolescence Cross-Sectional Study. Int J Obes (Lond) 32, 4-11.

34. Beghin L, Castera M, Manios Y, et al. (2008) Quality assurance of ethical issues and regulatory aspects relating to good clinical practices in the HELENA Cross-sectional Study. Int J Obes (Lond) 32, 12-18.

35. FAO/WHO/UNU Expert Panel (1985) Energy and Protein Requirements. Report of a Joint FAO/WHO/UNU Expert Consultation. World Health Organ Technical Report Series. Geneva: WHO.

36. Black AE (2000) Critical evaluation of energy intake using the Goldberg cut-off for energy intake:basal metabolic rate. A practical guide to its calculation, use and limitations. Int J Obes Relat Metab Disord 24, 1119-1130.

37. Biro G, Hulshof KF, Ovesen L, et al. (2002) Selection of methodology to assess food intake. Eur J Clin Nutr $\mathbf{5 6}$, Suppl. 2, S25-S32.

38. Vereecken CA, Covents M, Matthys C, et al. (2005) Young adolescents' nutrition assessment on computer (YANA-C). Eur J Clin Nutr 59, 658-667.

39. Vereecken CA, Covents M, Sichert-Hellert W, et al. (2008) Development and evaluation of a self-administered computerized 24-h dietary recall method for adolescents in Europe. Int J Obes (Lond) 32, 26-34.

40. Huybrechts I, Vereecken C, De Bacquer D, et al. (2010) Reproducibility and validity of a diet quality index for children assessed using a FFQ. Br J Nutr 104, 135-144.

41. VIGeZ (2006) De actieve voedingsdrieboek: een praktische voedings- en beweeggids (The Active Food Pyramid: A Practical Guide to Diet and Physical Activity). Brussels: Vlaams
Instituut voor Gezondheidspromotie en Ziektepreventie (VIGeZ).

42. Vyncke K, Cruz-Fernandez E, Fajó-Pascual M, et al. (2012) Validation of the Diet Quality Index for Adolescents by comparison with biomarkers, nutrient and food intakes: the HELENA study. Br J Nutr (epublication ahead of print version 30 October 2012).

43. Belgian Health Council (2012) Voedingsaanbevelingen voor België. Herziene versie 2009 (Nutritional Recommendations for Belgium. Revised Version 2009). Brussels: Belgian Health Council.

44. World Health Organization (2003) Diet, Nutrition and the Prevention of Chronic Diseases. WHO Technical Report Series no. 916. Geneva: WHO.

45. The European Food Information Council (EUFIC) (2011) http://www.eufic.org/article/en/page/RARCHIVE/expid/foodbased-dietary-guidelines-in-europe/ (accessed 20 August 2012).

46. Nagy E, Vicente-Rodriguez G, Manios Y, et al. (2008) Harmonization process and reliability assessment of anthropometric measurements in a multicenter study in adolescents. Int $J$ Obes (Lond) 32, 58-65.

47. Cole TJ, Bellizzi MC, Flegal KM, et al. (2000) Establishing a standard definition for child overweight and obesity worldwide: international survey. BMJ 320, 1240-1243.

48. Slaughter MH, Lohman TG, Boileau RA, et al. (1988) Skinfold equations for estimation of body fatness in children and youth. Hum Biol 60, 709-723.

49. Rodriguez G, Moreno LA, Blay MG, et al. (2005) Body fat measurement in adolescents: comparison of skinfold thickness equations with dual-energy X-ray absorptiometry. Eur J Clin Nutr 59, 1158-1166.

50. Tanner JM \& Whitehouse RH (1976) Clinical longitudinal standards for height, weight, height velocity, weight velocity, and stages of puberty. Arch Dis Child 51, 170-179.

51. Iliescu C, Beghin L, Maes L, et al. (2008) Socioeconomic questionnaire and clinical assessment in the HELENA Cross-sectional Study: methodology. Int J Obes (Lond) 32, $19-25$.

52. Hagstromer M, Bergman P, De Bourdeaudhuij I, et al. (2008) Concurrent validity of a modified version of the International Physical Activity Questionnaire (IPAQ-A) in European adolescents: The HELENA Study. Int J Obes (Lond) 32, 42-48.

53. Haerens L, Deforche B, Maes L, et al. (2007) Physical activity and endurance in normal weight versus overweight boys and girls. J Sports Med Phys Fitness 47, 344-350.

54. Nedeltcheva AV, Kilkus JM, Imperial J, et al. (2009) Sleep curtailment is accompanied by increased intake of calories from snacks. Am J Clin Nutr 89, 126-133.

55. Landhuis CE, Poulton R, Welch D, et al. (2008) Childhood sleep time and long-term risk for obesity: a 32-year prospective birth cohort study. Pediatrics 122, 955-960.

56. National Sleep Foundation (2002) 'Sleep in America' Poll. Washington, DC: National Sleep Foundation.

57. Gangwisch JE (2009) Epidemiological evidence for the links between sleep, circadian rhythms and metabolism. Obes Rev 10, 37-45.

58. Durmer JS \& Dinges DF (2005) Neurocognitive consequences of sleep deprivation. Semin Neurol 25, 117-129.

59. St-Onge MP, McReynolds A, Trivedi ZB, et al. (2012) Sleep restriction leads to increased activation of brain regions sensitive to food stimuli. Am J Clin Nutr 95, 818-824.

60. Diethelm K, Remer T, Jilani H, et al. (2011) Associations between the macronutrient composition of the evening meal and average daily sleep duration in early childhood. Clin Nutr 30, 640-646. 
61. Rey-Lopez JP, Vicente-Rodriguez G, Ortega FB, et al. (2010) Sedentary patterns and media availability in European adolescents: The HELENA study. Prev Med 51, 50-55.

62. Lockley SW, Skene DJ \& Arendt J (1999) Comparison between subjective and actigraphic measurement of sleep and sleep rhythms. J Sleep Res 8, 175-183.

63. Wolfson AR, Carskadon MA, Acebo C, et al. (2003) Evidence for the validity of a sleep habits survey for adolescents. Sleep 26, 213-216.

64. Ottevaere C, Huybrechts I, De Bourdeaudhuij I, et al. (2011) Comparison of the IPAQ-A and actigraph in relation to $\mathrm{VO}_{2 \max }$ among European adolescents: the HELENA study. J Sci Med Sport 14, 317-324.

\section{Appendix: HELENA Study Group}

\section{Co-ordinator: Luis A. Moreno}

Core Group members: Luis A. Moreno, Fréderic

Gottrand, Stefaan De Henauw, Marcela González-Gross, Chantal Gilbert

Steering Committee: Anthony Kafatos (President), Luis A. Moreno, Christian Libersa, Stefaan De Henauw, Jackie Sánchez, Fréderic Gottrand, Mathilde Kersting, Michael Sjöstrom, Dénes Molnár, Marcela González-Gross, Jean Dallongeville, Chantal Gilbert, Gunnar Hall, Lea Maes, Luca Scalfi Project Manager: Pilar Meléndez

\section{Universidad de Zaragoza (Spain)}

Luis A. Moreno, Jesús Fleta, José A. Casajús, Gerardo Rodríguez, Concepción Tomás, María I. Mesana, Germán Vicente-Rodríguez, Adoración Villarroya, Carlos M. Gil, Ignacio Ara, Juan Revenga, Carmen Lachen, Juan Fernández Alvira, Gloria Bueno, Aurora Lázaro, Olga Bueno, Juan F. León, Jesús Maㅡ Garagorri, Manuel Bueno, Juan Pablo Rey López, Iris Iglesia, Paula Velasco, Silvia Bel

\section{Consejo Superior de Investigaciones Cientificas (Spain)}

Ascensión Marcos, Julia Wärnberg, Esther Nova, Sonia Gómez, Esperanza Ligia Díaz, Javier Romeo, Ana Veses, Mari Angeles Puertollano, Belén Zapatera, Tamara Pozo, David Martínez.

\section{Université de Lille 2 (France)}

Laurent Beghin, Christian Libersa, Frédéric Gottrand, Catalina Iliescu, Juliana Von Berlepsch

Research Institute of Child Nutrition Dortmund, Rheinische Friedrich-Wilhelms-Universität Bonn (Germany)

Mathilde Kersting, Wolfgang Sichert-Hellert, Ellen Koeppen Pécsi Tudományegyetem (University of Pécs) (Hungary)

Dénes Molnar, Eva Erhardt, Katalin Csernus, Katalin Török, Szilvia Bokor, Angela Angster, Enikö Nagy, Orsolya Kovács, Judit Repásy

University of Crete School of Medicine (Greece)

Anthony Kafatos, Caroline Codrington, María Plada, Angeliki Papadaki, Katerina Sarri, Anna Viskadourou, Christos Hatzis, Michael Kiriakakis, George Tsibinos, Constantine Vardavas, Manolis Sbokos, Eva Protoyeraki, Maria Fasoulaki

Institut für Ernährungs- und Lebensmittelwissenschaften Ernährungphysiologie. Rheinische Friedrich Wilhelms Universität (Germany)
Peter Stehle, Klaus Pietrzik, Marcela González-Gross, Christina Breidenassel, Andre Spinneker, Jasmin Al-Tahan, Miriam Segoviano, Anke Berchtold, Christine Bierschbach, Erika Blatzheim, Adelheid Schuch, Petra Pickert

University of Granada (Spain)

Manuel J. Castillo, Ángel Gutiérrez, Francisco B. Ortega, Jonatan R Ruiz, Enrique G. Artero, Vanesa España-Romero, David Jiménez-Pavón, Palma Chillón. Magdalena CuencaGarcía

Istituto Nazionalen di Ricerca per gli Alimenti e la Nutrizione (Italy)

Davide Arcella, Elena Azzini, Emma Barrison, Noemi Bevilacqua, Pasquale Buonocore, Giovina Catasta, Laura Censi, Donatella Ciarapica, Paola D'Acapito, Marika Ferrari, Myriam Galfo, Cinzia Le Donne, Catherine Leclercq, Giuseppe Maiani, Beatrice Mauro, Lorenza Mistura, Antonella Pasquali, Raffaela Piccinelli, Angela Polito, Raffaella Spada, Stefania Sette, Maria Zaccaria

University of Napoli "Federico II" Dept of Food Science (Italy)

Luca Scalfi, Paola Vitaglione, Concetta Montagnese

Ghent University (Belgium)

Ilse De Bourdeaudhuij, Stefaan De Henauw, Tineke De Vriendt, Lea Maes, Christophe Matthys, Carine Vereecken, Mieke de Maeyer, Charlene Ottevaere, Inge Huybrechts

Medical University of Vienna (Austria)

Kurt Widhalm, Katharina Phillipp, Sabine Dietrich, Birgit Kubelka Marion Boriss-Riedl

\section{Harokopio University (Greece)}

Yannis Manios, Eva Grammatikaki, Zoi Bouloubasi, Tina Louisa Cook, Sofia Eleutheriou, Orsalia Consta, George Moschonis, Ioanna Katsaroli, George Kraniou, Stalo Papoutsou, Despoina Keke, Ioanna Petraki, Elena Bellou, Sofia Tanagra, Kostalenia Kallianoti, Dionysia Argyropoulou, Katerina Kondaki, Stamatoula Tsikrika, Christos Karaiskos.

Institut Pasteur de Lille (France)

Jean Dallongeville, Aline Meirhaeghe

Karolinska Institutet (Sweden)

Michael Sjöstrom, Patrick Bergman, María Hagströmer, Lena Hallström, Mårten Hallberg, Eric Poortvliet, Julia Wärnberg, Nico Rizzo, Linda Beckman, Anita Hurtig Wennlöf, Emma Patterson, Lydia Kwak, Lars Cernerud, Per Tillgren, Stefaan Sörensen

Asociación de Investigación de la Industria Agroalimentaria (Spain)

Jackie Sánchez-Molero, Elena Picó, Maite Navarro, Blanca Viadel, José Enrique Carreres, Gema Merino, Rosa Sanjuán, María Lorente, María José Sánchez, Sara Castelló

Campden and Chorleywood Food Research Association (United Kingdom)

Chantal Gilbert, Sarah Thomas, Elaine Allchurch, Peter Burguess

SIK - Institutet foer Livsmedel och Bioteknik (Sweden)

Gunnar Hall, Annika Astrom, Anna Sverkén, Agneta Broberg

Meurice Recherche \& Development asbl (Belgium)

Annick Masson, Claire Lehoux, Pascal Brabant, Philippe Pate, Laurence Fontaine 
Campden and Chorleywood Food Development Institute (Hungary)

Andras Sebok, Tunde Kuti, Adrienn Hegyi

Productos Aditivos SA (Spain)

Cristina Maldonado, Ana Llorente

Cárnicas Serrano SL (Spain)

Emilio García

Cederroth International AB (Sweden)

Holger von Fircks, Marianne Lilja Hallberg, Maria Messerer

Lantmännen Food RED (Sweden)
Mats Larsson, Helena Fredriksson, Viola Adamsson, Ingmar Börjesson

European Food Information Council (Belgium) Laura Fernández, Laura Smillie, Josephine Wills Universidad Politécnica de Madrid (Spain)

Marcela González-Gross, Jara Valtueña, David JiménezPavón, Ulrike Albers, Raquel Pedrero, Agustín Meléndez, Pedro J. Benito, Juan José Gómez Lorente, David Cañada, Alejandro Urzanqui, Juan Carlos Ortiz, Francisco Fuentes, Rosa María Torres, Paloma Navarro 